\title{
Assessment measures in systemic lupus erythematosus
}

\author{
Eutília Andrade Medeiros Freire ${ }^{1}$, Laís Medeiros Souto ${ }^{2}$, Rozana Mesquita Ciconelli
}

\begin{abstract}
Systemic lupus erythematosus (SLE) is a chronic inflammatory, multisystem, autoimmune and multifactorial disease, whose diagnosis is based on clinical and laboratorial parameters. This study aimed at investigating assessing measures in SLE available in the literature by using the method of integrative review of the literature. The bibliographic research was conducted through the search for scientific articles indexed in general health sciences databases, such as the Latin American and Caribbean Health Sciences (LILACS), MEDLINE/PubMed, and Scientific Electronic Library Online (SCIELO). The following descriptors were used: "assessment and lupus"; "quality of life and lupus"; "damage and lupus"; "activity index and lupus"; and "patient outcomes and lupus". The selected publications showed three domains of SLE assessment: assessing measures of disease activity; assessing measures of damage caused by the disease; and assessing measures of quality of life. The study showed that the patients' perception of health status and quality of life and the impact of the disease and its treatment can be better evaluated using the measures proposed by the authors.
\end{abstract}

Keywords: systemic lupus erythematosus, damage assessment, outcome assessment (health care), quality of life.

[Rev Bras Reumatol 2011;51(1):70-80] CElsevier Editora Ltda.

\section{INTRODUCTION}

Systemic lupus erythematosus (SLE) is a chronic inflammatory disease of the connective tissue, of multifactorial etiology, characterized by affecting several organs and systems and being accompanied by important immune disorders. It has autoantibodies directed mainly against nuclear antigens, some of which participate in immune-mediated tissue injuries. Although it can affect both sexes and any age bracket, its incidence is higher among women (10:1), with a peak around 30 years of age. ${ }^{1}$

Despite its unknown etiology, a set of the following different factors are believed to trigger SLE: genetic factors, supported by the higher prevalence of SLE among first- and second-degree relatives; environmental factors, specially ultraviolet radiation; viral infections; chemical substances; sexual hormones; and emotional factors. The interaction among those multiple factors is associated with loss of immune regulation, loss of immune tolerance, development of autoantibodies, deficient removal of immune complexes, and activation of the complement system and other inflammatory processes that lead to cell and/or tissue injury.

The clinical manifestations of SLE vary, and can affect any organ or system, in isolation or simultaneously, at any phase of the disease. Systemic lupus erythematosus affects mainly the joints, skin, blood cells, blood vessels, serous membranes, kidneys, and brain.

Being a multisystem disease, frequently of insidious onset and variable clinical presentation, the diagnosis of SLE can be difficult, mainly on an initial assessment. No clinical or laboratory alteration in isolation makes the diagnosis of SLE, although many of such alterations can be very suggestive of the disease. In 1982, the American College of Rheumatology (ACR) proposed the criteria for classifying SLE, ${ }^{2}$ which were reviewed in 1997. ${ }^{3}$ Initially, the criteria elaboration aimed at homogenizing

Submitted on 7/30/2010. Approved on 12/8/2010. We declare no conflict of interest.

Department of Internal Medicine of the Universidade Federal da Paraíba (UFPB) and Department of Medicine of the Universidade Federal de São Paulo (Unifesp).

1. PhD, Professor of the Discipline of Rheumatology at the Universidade Federal da Paraíba - UFPB

2. Medical student at the Universidade Federal da Paraíba - UFPB

3. PhD, Professor of the Discipline of Rheumatology at the Universidade Federal de São Paulo - Unifesp

Correspondence to: Eutília Andrade Medeiros Freire. Av. Cabo Branco, 3524/apt 501B. João Pessoa, PB, Brazil. CEP: 58045-110.

E-mail: eutilia@terra.com.br. 
populations for scientific studies. However, because of their high sensitivity and specificity, in clinical practice, the criteria are often used for diagnosing patients with SLE.

Disease activity is mainly controlled by the use of corticosteroids and immunosuppressive drugs, which have several side effects, such as arterial hypertension, diabetes, osteoporosis, and neoplasias. Thus, identifying and even predicting disease activity is paramount for the proper planning of disease treatment. Serological tests can be used to assess disease activity, the most important being measuring anti-dsDNA antibodies, levels of complement and its products, and serum levels of interleukins, specially IL-6, IL-10, and IL-16. No serological marker correlates with disease activity in all patients. ${ }^{4}$

The SLE prevalence has increased, as mortality has decreased over the years, because of the development of new therapeutic options and appearance of more sensitive and specific immunological and genetic tests for an earlier diagnosis. Currently, the 5-year survival in SLE is estimated to range from $97 \%$ to $80 \% .^{5,6}$ That increase in survival leads to the occurrence of sequelae and disability due to the disease itself or its treatment, involving personal care, locomotion, agility, behavior, communication, well-being, and other activities. ${ }^{7,8,9}$

Because the disease is chronic and incurable, the treatment is aimed at suppressing disease activity, which is reversible, and at preventing the appearance of organ injuries caused by the disease, and of side effects secondary to the drugs used, in addition to controlling associated comorbidities. ${ }^{10}$

During the clinical follow-up of a patient with SLE, the physician should answer the following questions: has the disease improved, worsened, or remained stable?; is the presence of irreversible injury due to the disease or to the treatment instituted?; what is the patient's perception about his/her health status and quality of life, since it often differs from that of the physician? ${ }^{11}$

Regarding patients who survived longer than 10 years, the cause of death almost always does not relate to the SLE activity but to chronic injuries caused by the disease or its treatment. ${ }^{12}$ For the prognosis of SLE, patients should be assessed for disease activity, injuries accumulated during the disease, and quality of life.

This study aimed at investigating measures for SLE assessment available in the literature.

\section{MATERIAL AND METHODS}

For the present study, the method chosen was the integrative review of the literature, which aims at gathering and summarizing results of research done on a certain theme or question, in a systematic and ordered way, contributing to deepen knowledge on the investigated theme. ${ }^{13}$ That method summarizes the already concluded studies and provides conclusions from a theme of interest, differing from the systematic review. While the systematic review includes only experimental studies, the integrative review has a broader approach, including experimental and quasi-experimental studies, and theoretical and empiric studies. The elaboration process of the integrative review follows carefully six stages: selection of hypotheses or questions for review; selection of the research that will constitute the review sample; definition of the characteristics of the primary research constituting the review sample; interpretation of the results; and report of the review providing a critical exam of the findings. ${ }^{14}$

The bibliographic survey of this review consisted in searching for scientific articles indexed in general health sciences databases, such as LILACS (Latin American and Caribbean Health Science journals), MEDLINE/PubMed, and Scientific Electronic Library Online (SCIELO). The descriptors used in the search were as follows: "assessment and lupus"; "quality of life and lupus"; "damage and lupus"; "activity index and lupus"; and "patient outcomes and lupus".

The inclusion criteria used for selecting the sample were as follows: full texts available through access to the portal of periodicals of the Brazilian Coordination for the Improvement of Higher-Level-Education Personnel (CAPES); and analysis of the variables considered in the study (assessment measures). The most relevant publications were selected and their data analyzed and presented in a discursive and narrative way.

\section{RESULTS AND DISCUSSION}

\section{Measures for assessing disease activity}

Disease activity indices have been created aiming at standardizing the SLE activity assessment. Some of such indices are as follows: ECLAM (European Consensus Lupus Activity Measurement); LAI (Lupus Activity Index); SLAM (Systemic Lupus Activity Measure); BILAG (British Isles Lupus Assessment Group); and SLEDAI (Systemic Lupus Erythematosus Disease Activity Index). The last three indices proved to be reproducible and valid, and to have good intercorrelation. ${ }^{15}$

The ECLAM index assesses disease activity over the previous month, and comprises 15 clinical and laboratory parameters, with scores ranging from 0 to $10 .{ }^{10}$ Its reliability, 
validity, and sensitivity to detect changes have been evaluated in several studies, and it has a good correlation with other indices used.

LAI includes four scores for the physician's global evaluation and his/her opinion regarding disease severity, laboratory findings, and immunosuppressive treatment. Its mean ranges from 0 to 3 . Variations of 0.26 are considered alterations for disease activity. ${ }^{10}$

SLEDAI has been used for assessing disease activity in several centers, ${ }^{16}$ and its validity and reproducibility have been evaluated in Brazil. ${ }^{17}$ It takes into consideration the organ affected and includes clinical and laboratory parameters in its evaluation. SLEDAI assesses disease activity in the previous 10 days. Scores greater than 8 indicate active disease. A three-point variation between medical visits is considered disease activation, and variations greater than or equal to 12 points mean severe activity. ${ }^{18}$ In the year 2000 , SLEDAI was reviewed, originating SLEDAI-2K. ${ }^{19}$ The modification proposed included the persistent activity of some parameters, instead of those parameters' scores only at their beginning or relapse. Gladman et al. ${ }^{19}$ showed that the persistence of rash, mucosal ulcers, alopecia, and proteinuria greater than $0.5 \mathrm{~g}$ in $24 \mathrm{~h}$ can be used in studies to assess disease activity, when comparing SLEDAI-2K and original SLEDAI. Uribe et al. ${ }^{20}$ assessed three different instruments used to measure SLE activity [modified SLAM, Mexican SLEDAI (Mex-SLEDAI), and modified SLEDAI-2K (without the serological parameters: anti-dsDNA and serum complement)] and compared them with SLEDAI-2K and with the physician's global evaluation of disease activity. Those authors concluded that the three instruments correlated well with SLEDAI-2K and with the physician's global evaluation. In addition, the modified SLEDAI-2K had the best discriminative validity (ability to differentiate clearly active patients from inactive ones or those with minimum activity) and the lowest cost among the three instruments assessed.

The BILAG index also measures SLE clinical activity and was developed on the principle of the physician's intention-totreat. That index is composed of eight organ-based systems, and no total score is calculated. Instead, the BILAG index reports disease activity in each of the eight organ-based systems separately (general symptoms, mucocutaneous, respiratory, cardiovascular, neurological, musculoskeletal, renal, and hematological systems), depending on the clinical characteristics present and their behavior in the preceding four weeks (whether they are new or the same, aggravated or improved). It is represented with alphabetical letters. BILAG " $A$ " represents the presence of one or more severe
SLE characteristics. BILAG " $\mathrm{B}$ " indicates more moderate characteristics of the disease. BILAG "C" includes only mild symptomatic characteristics. BILAG "D" represents only the previous activity, with no current symptoms caused by active lupus. BILAG "E" indicates that a system has never been involved. This is an understandable and flexible instrument, used as a transitional index of easy and fast application. ${ }^{21,22}$

\section{Measures for assessing the damage caused by SLE}

Instruments for assessing the damage index in organ-based systems, detecting damages in patients regardless of their cause, which could have resulted from disease activity or treatment and also comorbidities, should be used as a health measure in patients with chronic diseases. To avoid confusion between disease activity and damage, the symptom has to be present for at least six months, causing tissue damage, which results in irreversible organ damage.

In 1996, ACR published the initial validation of an instrument for assessing damage indices in LES, the Systemic Lupus International Collaborating Clinics/American College of Rheumatology - Damage Index (SLICC/ACR-DI). ${ }^{23}$ That instrument approaches 12 organ-based systems, detecting damages in patients regardless of their cause, which can have resulted from disease activity or treatment or concomitant diseases, such as cancer and diabetes.

The organ and psychic damages affecting patients who survive longer often result in physical or mental disabilities and deficiencies, worsening the patients' quality of life, which has been recognized as an important indicator of the health status of patients with chronic diseases. ${ }^{24}$

\section{Measures for assessing quality of life}

Health-related quality of life (QoL) scales measure changes in physical function, functional, psychological and social aspects, and reflect the patient's perception of his/her health status. ${ }^{25}$ The term QoL began to be used in the USA after the Second World War aiming at describing the effect generated by the acquisition of material goods (technology) in people's life. It was only some years later that it began to be considered an important parameter, aiming at advances in the health and education areas. In the medical-social literature, QoL has been related to a variety of terms, including life satisfaction, selfesteem, well-being, happiness, health, life value and meaning, functional status, and adjustment. ${ }^{26}$

According to the WHO, health is defined as the individual's perception about his/her physical, mental, and social wellbeing, and not merely the absence of disease or infirmity. ${ }^{27}$ 
It is a comprehensive concept that comprises physical health, psychological status, degree of independence, social relationship, beliefs, relationship with the environment, financial gain, and freedom. The measures to assess health-related QoL correspond to a more limited evaluation of QoL, referring to the dimensions specifically and directly related to the health status. That concept is often referred to in the medical literature as health-related QoL, health status, and functional status..$^{27,28}$

Although the survival of SLE patients has increased in the past 50 years, their QoL remains poor. The measures for assessing damages and disease activity consider neither the patients' perspective of the disease nor their QoL..$^{29}$ Thus, QoL assessment is an important parameter for measuring the impact of chronic diseases. Physiological measurements provide fundamental information for clinicians, but often correlate poorly with functional capacity and well-being, aspects patients are more interested in and acquainted with. Quality of life should be measured as follows: in clinical research, aiming at observing the impact of the disease as a complementary qualitative measure; in clinical practice evaluation, considering the patient's perspective whenever decisions regarding the disease should be made; and in health economic analyses, which study the impact of medical actions measured in both quantitative (effectiveness and tolerance) and qualitative (QoL) terms, and their relation with the expenditure of financial resources. ${ }^{30,31}$

Most instruments for QoL assessment comprise a number of items or questions. The items are grouped into domains or dimensions. One domain relates to the behavior or experience area being measured. Domains can include questions about physical, emotional, and social functions.

The instruments for QoL assessment can be generic or specific for a certain disease. The generic instruments can be applied to a large variety of diseases and populations, because they include aspects relating to function, dysfunction, and emotional and physical discomfort, which are relevant to the QoL of individuals in general.

The Medical Outcomes Study 36-Item Short-Form Health Survey (SF-36) is a generic instrument for QoL assessment, easily managed and understood. ${ }^{32}$ It is a multidimensional questionnaire formed by 35 items, grouped into the following eight domains: physical functioning; role limitations due to physical health; pain; general health perception; vitality; social functioning; role limitations due to emotional problems; and mental health. It includes one more question about the current health perception as compared with that of one year before, which is not included in the score calculation. The final score ranges from zero to 100 , in which zero corresponds to the worst general health perception and 100 to the best general health perception. Ciconelli et al. ${ }^{33}$ translated the SF-36 into Portuguese and validated it, and the Portuguese version was later applied to patients with rheumatoid arthritis, SLE, and other rheumatological and non-rheumatological diseases.

Additionally, in assessing the generic health profile, there is a preference-based system aimed at measuring health status, and that produces a utility score. Assessing health utility measures provides information about the patients' experiences with the disease or therapy, the efficacy, effectiveness, and efficiency of interventions and health care, and the health status of a population in general. The scores of those systems are based on the preference for health status in a generic scale that ranges from 0.00 (death) to 1.00 (perfect health). That health status classification is generic and applicable to all individuals in different clinical situations and to the population in general.

Specific instruments assess QoL for a primary area of interest. They can be specific for a certain disease, for a certain function, or for a problem. Their most important characteristic is sensitivity to detect changes after an intervention.

Questionnaires assessing QoL can be self-administered or interview-administered. Because of social-economic reasons, in studies carried out in Brazil, data have been collected through interviews. ${ }^{34,35}$

In 2003, the validation of a specific questionnaire for SLE, the Systemic Lupus Erythematosus Symptom Checklist (SSC) was published, aimed at measuring the impact of the disease and its treatment on the individual. ${ }^{36}$ That questionnaire approaches the presence and impact of 38 symptoms related to SLE and/or its treatment in a four-point scale, where zero is the best health status and four, the worst.

The internal consistency, reproducibility, and validity have been tested in 87 patients with SLE with coefficients of 0.89 , 0.67 , and 0.87 , respectively, indicating satisfactory correlation indices for that questionnaire. Comparison with other QoL instruments has shown moderate correlations. Responsiveness was tested in 17 patients with lupus nephritis at the beginning of treatment with cyclophosphamide and one year after, and significant changes were observed in several symptoms related to the disease. That questionnaire was translated into Portuguese and validated by Freire et al. in $2007 .^{37}$

Leong et $a l .{ }^{38}$ have published the development and preliminary validation in English of the Systemic Lupus Erythematosus Quality of Life Questionnaire (SLEQOL). That questionnaire comprises 40 items divided into the following six domains: physical functioning; occupational activity; symptoms; treatment; mood; and self-image. In each domain, the scores vary from 1 to 7 , and the higher the score, the worse the QoL. The minimum score is 40 and the 
maximum, 280. It has been tested in 275 patients with SLE, the internal consistency (Cronbach coefficient) being 0.95 and intraobserver reproducibility, 0.83 . Responsiveness was tested by using the global health assessment scale, ranging from +7 to -7 , and the SLEQOL questionnaire underwent several statistical treatments that showed it was more sensitive than SF-36 to changes over time. ${ }^{38}$ That questionnaire was also translated into Brazilian Portuguese and validated by Freire in $2008 .{ }^{39}$

New questionnaires have been recently developed and published focusing the needs and QoL of SLE patients.

The Systemic Lupus Erythematosus Needs Questionnaire (SLENQ) has seven domains that assess the following needs: psychological/spiritual/existential; health services; health information; physical; social support; daily living; and employment/financial. The questionnaire showed good coefficients of reproducibility and moderate correlations with $\mathrm{SF}-36 .^{40}$

The Lupus Quality of Life (LupusQoL) proved to be a valid instrument to assess QoL. It contains 34 items distributed in the following eight domains: physical health; emotional health; body image; pain; planning; fatigue; intimate relationships; and burden to others. ${ }^{41}$
As health-related QoL scales are part of the assessment of patient-reported outcomes (Pros) throughout a disease, instruments that measure subjective symptoms and satisfaction with treatment also integrate that assessment. Over the past two decades, the outcomes of assessment measures centered on the patient's opinion have played an important role in the study of chronic diseases. In the ACR, the committee on Outcome Measures in Rheumatology Clinical Trials (OMERACT) has recognized the importance of measuring functioning and wellbeing from the patient's viewpoint as a criterion to determine clinical improvement. In clinical trials, such QoL instruments have been largely used as the primary objective, because of recommendations to consider the patients' own assessment about their health status, since they are the most interested individuals in their own outcome.

\section{FINAL CONSIDERATIONS}

The patient's perception of his/her health status and QoL, as well as of the impact of his/her disease and treatment, has been widely recognized as research topics in clinical trials and epidemiologic studies. Thus, understanding such measures for their use in daily clinical practice is paramount. 


\section{REFERENCES}

\section{REFERÊECIAS}

1. Danchenko N, Satia JA, Anthony MS. Epidemiology of systemic lupus erythematosus: a comparation of worldwide disease burden. Lupus 2006; 15(5):308-18.

2. Tan EM, Cohen AS, Fries JF, Masi AT, McShane DJ, Rothfield NF et al. The 1982 revised criteria for the classification of systemic lupus erythematosus. Arthritis Rheum 1982; 25(11):1271-7.

3. Hochberg MC. Updating the American College of Rheumatology revised criteria for the classification of systemic lupus erythematosus. Arthritis Rheum 1997; 40(9):1725.

4. Isenberg DA, Colaco CB, Dudeney C, Todd-Pokropek A, Snaith ML. The relationship of anti-DNA antibody idiotypes and anti-cardiolipin antibodies to disease activity in systemic lupus erythematosus. Medicine (Baltimore) 1986; 65(1):46-55.

5. Pistiner M, Wallace DJ, Nessim S, Metzger AL, Klinenberg JR. Lupus erythematosus in the 1980s: a survey of 570 patients. Semin Arthritis Rheum 1991; 21(1):55-64.

6. MacGowan JR, Ellis S, Griffiths M, Isenberg DA. Retrospective analysis of outcome in a cohort of patients with lupus nephritis treated between 1977 and 1999. Rheumatology (Oxford) 2002; 41(9):981-7.

7. Hochberg MC, Boyd RE, Ahearn JM, Arnett FC, Bias WB, Provost TT et al. Systemic lupus erythematosus: a review of clinicolaboratory features and immunogenetic markers in 150 patients with emphasis on demographic subsets. Medicine (Baltimore) 1985; 64(5):285-95.

8. Ginzler E, Berg A. Mortality in systemic lupus erythematosus. J Rheumatol 1987; 14(Suppl 13):218-22.

9. Swaak AJ, Nossent JC, Bronsveld W, Van Rooyen A, Nieuwenhuys EJ, Theuns L et al. Systemic lupus erythematosus. I. Outcome and survival: Dutch experience with 110 patients studied prospectively. Ann Rheum Dis 1989; 48(6):447-54.

10. Griffiths B, Mosca M, Gordon C. Assessment of patients with systemic lupus erythematosus and the use of lupus disease activity indices. Best Pract Res Clin Rheumatol 2005; 19(5):685-708. 
11. Isenberg D, Ramsey-Goldman R. Assessing patients with lupus: towards a drug responder index. Rheumatology 1999; 38:1045-9.

12. Gladman D, Ginzler E, Goldsmith C, Fortin P, Liang M, SanchezGuerrero $\mathrm{J}$ et al. The development and initial validation of the Systemic Lupus International Collaborating Clinics/American College of Rheumatology damage index for systemic lupus erythematosus. Arthritis Rheum 1992; 39(3):363-9.

13. Mendes KDS, Silveira RCCP, Galvão CM. Revisão integrativa: método de pesquisa para a incorporação de evidências na saúde e na enfermagem. Texto contexto Enferm 2008; 17(4):758-64.

14. Bertolin DC, Pace AE, Kusumota L, Ribeiro RCHM. Modos de enfrentamento dos estressores de pessoas em tratamento hemodiálitico: revisão integrativa da literatura. Acta paul enferm 2008; 21(spe): 179-86.

15. Gladman DD, Goldsmith CH, Urowitz MB, Bacon P, Bombardier $\mathrm{C}$, Isenberg D et al. Crosscultural validation and reliability of three disease activity indices in systemic lupus erythematosus. J Rheumatol 1992; 19(4):608-11.

16. Bombardier C, Gladman DD, Urowitz MB, Caron D, Chang CH. Derivation of the SLEDAI. A disease activity index for lupus patients. The Comittee on Prognosis Studies in SLE. Arthritis Rheum 1992; 35(6):630-40.

17. Sato EI, Ferraz MB, Lourenzi VPM, Natour J, Ikedo F, Atra E. Estudo da reprodutibilidade e validade do índice de atividade do lupus eritematoso sistêmico. Rev Bras Reumatol 1991; 31(4):133-6.

18. Barr SG, Zonana-Nacach A, Magder LS, Petri M. Patterns of disease activity in systemic lupus erythematosus. Arthritis Rheum 1999; 42(12):2682-8.

19. Gladman DD, Ibañez D, Urowitz MB. Systemic lupus erythematosus disease activity index 2000. J Rheumatol 2002; 29(2):288-91.

20. Uribe AG, Vilá LM, McGwin GJr, Sanchez ML, Reveille JD, Alarcón GS. The Systemic Lupus Activity Measure-revised, the Mexican Systemic Lupus Erythematosus Disease Activity Index (SLEDAI), and a modified SLEDAI-2K are adequate instruments to measure disease activity in systemic lupus erythematosus. J Rheumatol 2004; 31(10):1934-40.

21. Hay EM, Bacon PA, Gordon C, Isenberg DA, Maddison P, Snaith ML et al. The BILAG index: a reliable and valid instrument for measuring clinical disease activity in systemic lupus erythematosus. Q J Med 1993; 86(7):447-58.

22. Isenberg DA, Rahman A, Allen E, Farewell V, Akil M, Bruce IN et al. BILAG 2004. Development and initial validation of an updated version of the British Isles Lupus Assessment Groups disease activity index for patients with systemic lupus erythematosus. Rheumatology (Oxford) 2005.

23. Gladman D, Ginzler E, Goldsmith C, Fortin P, Liang M, Urowitz $\mathrm{M}$ et al. The development and initial validation of the Systemic Lupus International Collaborating Clinics/American College of Rheumatology damage index for systemic lupus erythematosus. Arthritis Rheum 1996; 39(3):363-9.

24. Fallowfield LJ. Behavioural interventions and psychological aspects of care during chemotherapy. Eur J Cancer 1992; 28A(Suppl 1);S39-41.

25. Testa MA. The medical outcomes study. JAMA 1996; 275(14):1083; [author reply] 1084-5.
26. Carr AJ. Margaret Holroyd Prize Essay. A patient-centred approach to evaluation and treatment in rheumatoid arthritis: the development of a clinical tool to measure patient-perceived handicap. Br J Rheumatol 1996; 35(10):921-32.

27. Guyatt GH, Feeny DH, Patrick DL. Measuring health-related quality of life. Ann Intern Med 1993; 118(8):622-9.

28. Wilson IB, Kaplan S. Clinical practice and patients health status: how are the two related? Med Care 1995; 33(4 Suppl):AS209-14.

29. Toloza SM, Jolly M, Alarcón GS. Quality-of-Life Measurements in Multiethnic Patients with Systemic Lupus Erythematosus: CrossCultural Issues. Curr Rheumatol Rep 2010.

30. Testa MA, Simonson DC. Assesment of quality-of-life outcomes. N Engl J Med 1996; 334(13):835-40.

31. Halioua B, Beumont MG, Lunel F. Quality of life in dermatology. Int J Dermatol 2000; 39(11):801-6.

32. Ware JE Jr, Bayliss MS, Rogers WH, Kosinski M, Tarlov AR. Differences in 4-year health outcomes for elderly and poor, chronically ill patients treated in $\mathrm{HMO}$ and fee-for-service systems. Results from the Medical Outcomes Study. JAMA 1996; 276(13):1039-47.

33. Ciconelli, RM, Ferraz MB, Santos W, Meinão I, Quaresma MR. Tradução par a língua portuguesa e validação do questionário genérico de avaliação de qualidade de vida SF-36 (Brasil SF-36). Rev Bras Reumatol 1999; 39(3):143-50.

34. Ferraz MB, Oliveira LM, Araujo PM, Atra E, Tugwell P. Crosscultural reliability of the physical ability dimension of the health assessment questionnaire. J Rheumatol 1990; 17(6):813-7.

35. DAmorim AB. Avaliação das formas auto-administráveis dos questionários MHAQ e SF-12 em pacientes com doenças reumatológicas(Dissertação de Mestrado). UNIFESP. São Paulo, 2001.

36. Grootscholten C, Ligtenberg G, Derksen RH, Schreurs KM, de GlasVos JW, Hagen EC et al. Health-related quality of life in patients with systemic lupus erythematosus: development and validation of a lupus specific symptom checklist. Qual Life Res 2003; 12(6):635-44.

37. Freire EA, Guimarães E, Maia I, Ciconelli RM. Systemic lupus erythematosus symptom checklist cross-cultural adaptation to Brazilian Portuguese language and reliability evaluation. Acta Reumatol Port 2007; 32(4):341-344.

38. Leong KP, Kong KO, Thong BY, Koh ET, Lian TY, Teh CL et al. Development and preliminary validation of a systemic lupus erythematosus-specific quality-of-life instrument (SLEQOL). Rheumatology (Oxford) 2005; 44(10):1267-76.

39. Freire EAM. Avaliação da responsividade em qualidade de vida relacionada à saúde: Um estudo prospectivo em pacientes com lupus eritematoso sistêmico [tese]. São Paulo: Universidade Federal de São Paulo, Escola Paulista de Medicina, Programa de Pós-Graduação em Medicina; 2008.

40. Moses N, Wiggers J, Nicholas C, Cockburn J. Development and psychometric analysis of the systemic lupus erythematosus questionnaire (SLENQ). Qual Life Res 2007; 16(3):461-6.

41. McElhone K, Abbott J, Shelmerdine J, Bruce IN, Ahmad Y, Gordon C et al. Development and validation of a disese-specific healthy-related quality of life measure, the LupusQOL, for adults with systemic lupus erythematosus. Arthritis Rheum 2007; 57(6):972-9. 